\title{
To compare the oral hygiene status of patients with Straight wire appliance and Begg's appliance in the suburban population
}

Radhakrishna Gogineni ${ }^{1}$, Saritha ${ }^{2}$, Suryaprakash ${ }^{3}$

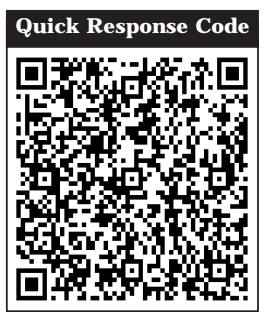

doi : 10.5866/2014.611443

${ }^{1}$ Professor

Department of Orthodontics,

P.M.N.M Dental College and Hospital,

Bagalkot, Karnataka

2Professor

Department of Conservative dentistry and

Endodontics, P.M.Nadagouda. Memorial Dental

College \& Hospital, Bagalkot

${ }^{3}$ Post Graduate Student

Department of Orthodontics and Dentofacial

Orthopaedics, P.M.Nadagouda. Memorial Dental

College \& Hospital, Bagalkot, Karnataka

\section{Article Info:}

Received: October 11, 2013

Review Completed: November 10, 2013

Accepted: December 12, 2013

Available Online: February, 2014 (www.nacd.in)

(c) NAD, 2014 - All rights reserved

\section{Email for correspondence:}

drrkgogineni@gmail.com

\begin{abstract}
:
Plaque is major etiological factor in the causation of periodontal disease. Orthodontic appliances are known to accumulate plaque owing to their complex configuration. This study is to evaluate the difference in plaque accumulation both quantitatively and qualitatively, and oral hygiene maintenance, between Begg's and Straight wire appliances. Forty patients between the ages of 13 years - 23 years, were subjected to oral prophylaxis to bring the plaque score to zero before the start of the study and were asked to report every 2 weeks to identify the microbial shift in plaque sample. The plaque samples were collected in $2 \mathrm{ml}$ of saline containing test tubes. The disclosing solution was applied on the labial and lingual tooth surfaces and the plaque was scored with help of Quigly \& Heins index. Data was analysed using SPSS software. $p<0.005$ was considered as the statistically significant level. Significant difference between group I and II for variables V1\& V2 at each time point. Also the group II patients are showing significant increase in plaque index value at each point. Inspite of maintaining same environment the plaque accumulation and spirochetes are more in straight wire appliance than Begg's and the flora is shifting to more pathogenic form.
\end{abstract}

Key words: Plaque, Spirochetes, Straight wire technique, Begg technique

\section{Introduction:}

Oral hygiene is one of the most important issues in patients undergoing orthodontic treatment. Although long-term reports concerning the health of the periodontal tissues of orthodontic. Patients are controversial,

1-2 oral hygiene measures are al ways instituted because bands, brackets, ligature wires, and el astics encourage accumulation of microbial flora and food residues, which, in time, cause periodontal diseases and caries. Although mechanical cleaning of tooth surfaces can be accomplished in various forms, ${ }^{3-8}$ tooth brushing is routinely advised to prevent or at least minimize these hazards.

\section{Indian Journal of Dental Advancements \\ Journal homepage: www. nacd. in}


Most papers on the management of oral hygiene in patients undergoing orthodontic treatment have concentrated on the effects of different oral-hygiene regimes $^{9-11}$, and on the efficacy of various oral-hygiene aids in plaque control and reduction of gingival inflammation ${ }^{12-13}$. Manual tooth brushing, one of the oldest methods of plaque removal, remains the mainstay of oral hygiene and plaque control. It is often used as the standard or control against which other methods of plaque removal are assessed ${ }^{12-13}$.

Chlorhexidine mouthwashes, as an adjunct to tooth brushing ${ }^{14}$ have been found effective in the control of gingival inflammation, although prolonged use may cause problems with staining. More recently, pre-brushing rinses have been introduced, though these show no difference in effect on plaque accumulation or gingival health ${ }^{15}$. Fluoride mouth rinses significantly reduce the extent of enamel decalcification and gingival inflammation during orthodontic treatment ${ }^{11,16-19}$. A number of studies have evaluated the effect of Mechanical aids, as compared with manual tooth brushing, on oral hygiene in orthodontic patients ${ }^{12,13}$. They found the use of electric toothbrushes brought a significant improvement in oral hygiene.

Obviously, oral hygiene is greatly complicated following the placement of fixed orthodontic appliances. Failure to manage plaque removal properly may lead to loss of tooth support ${ }^{20}$ and to an increased number of carious lesions. ${ }^{20}$

The hygiene situation in orthodontics is really challenging, if the orthodontist succeeds in making the patient hygiene minded, possible periodontal damage during treatment is, no doubt, ${ }^{21-22}$ compensated for in the long run. When the hygiene is neglected, on the other hand, more damage is initiated during treatment and, the patient being little motivated or able to control his periodontal situation, the long-term benefits of the orthodontic treatment might be questioned. It is generally conceded that the greater plaque-retentive nature of orthodontic appliances aids in the plaque accumulation at the gingival margin ${ }^{23}$ and thus may contribute to the incidence and severity of gingival inflammation.

The ongoing monitoring of gingival and periodontal health by orthodontists throughout the treatment period and repeated reinforcement of acceptable oral hygiene routines have become an integral part of modern orthodontic practice. ${ }^{24}$

BEGG \& STRAIGHT WIRE are the two commonly used orthodontic appliances, with different bracket sizes, configuration and mechanisms of tooth movements. ${ }^{25}$ In view of the different in brackets and the techniques it is possible that there is a difference in plaqueaccumulation and oral hygiene maintenance could be a point of speculation.

To the best of the our knowledge no studies have been carried out to evaluate the difference in plaque accumulation both quantitatively and qualitatively, and oral hygiene maintenance, between Begg's and Straight wire appliances, this study has been undertaken with the following aim:

"To compare the oral hygiene status of patients with straight wire appliance and Begg's appliance in the suburban population".

\section{Subjects and Methods:}

Forty patient attending the Department of Orthodontics, Saveetha Dental College and Hospital, between the ages of 13 years - 23 years, who were otherwise free from systemic diseases were invol ved in this study.

Subjects with the following criteria were chosen.

1. Subjects with no oral habits and individuals with no systemic or biochemical diseases

2. Those who were not under any drug coverage

3. Females who were neither on contraceptive pills nor were pregnant,

4. At least twenty four teeth present at the time of study,

5. Wereundergoing treatment with fixed appliance with no history of previous orthodontic treatment, 


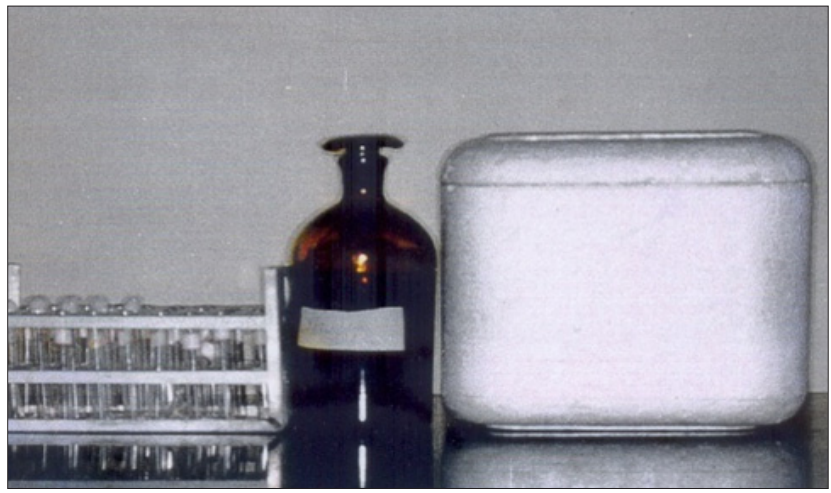

Figure - I

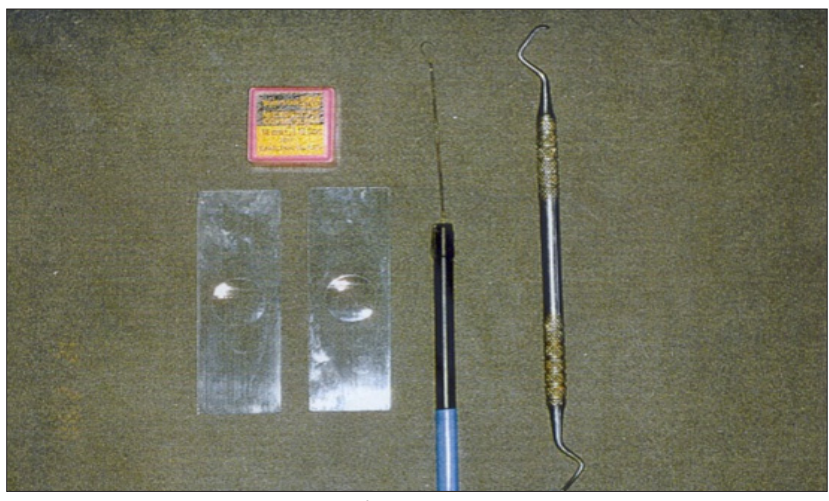

Figure - II

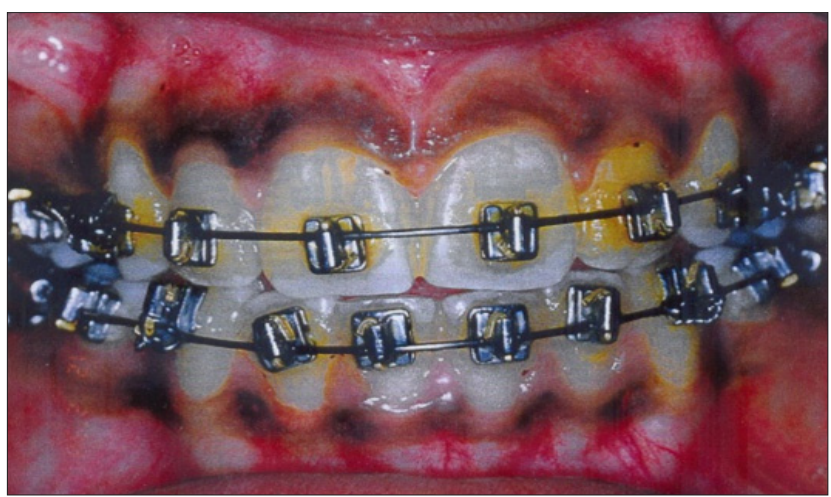

Figure - III

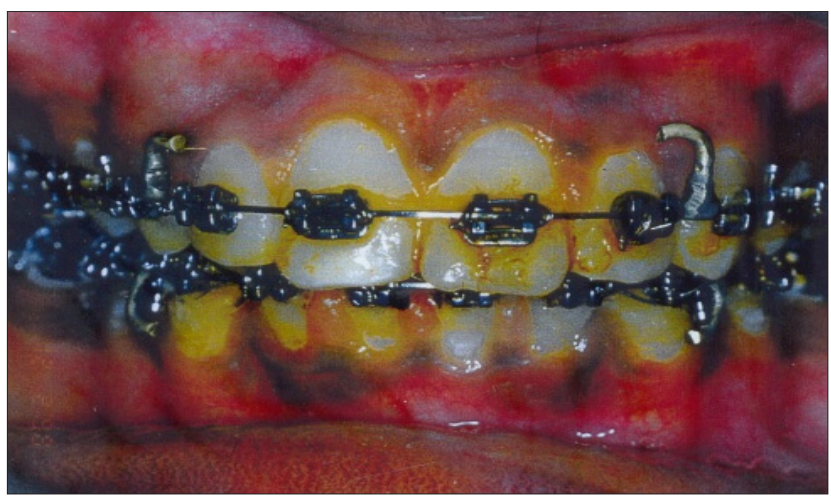

Figure - IV

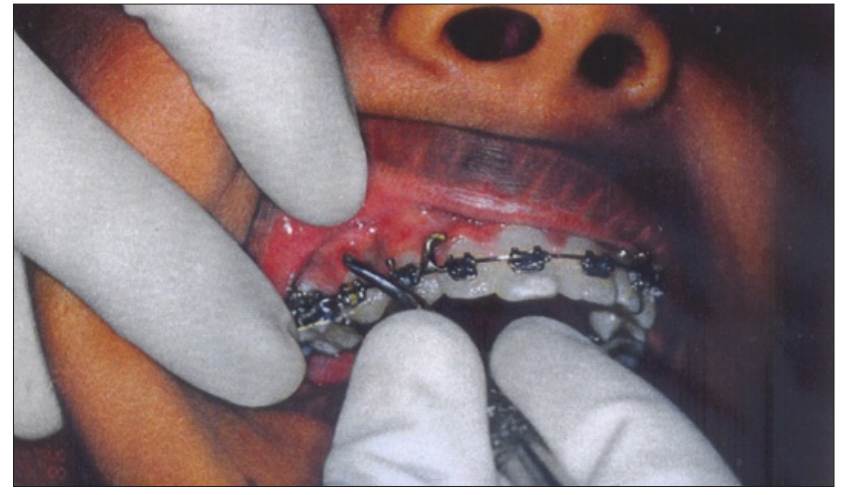

Figure - V

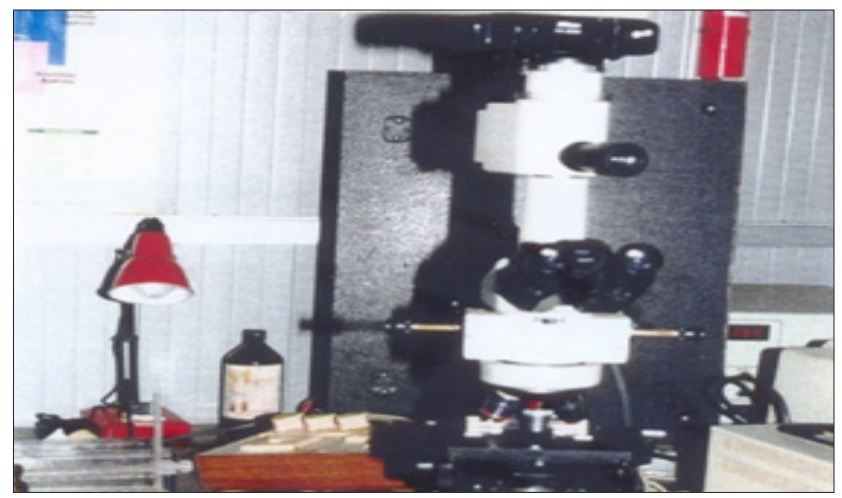

Figure - VI

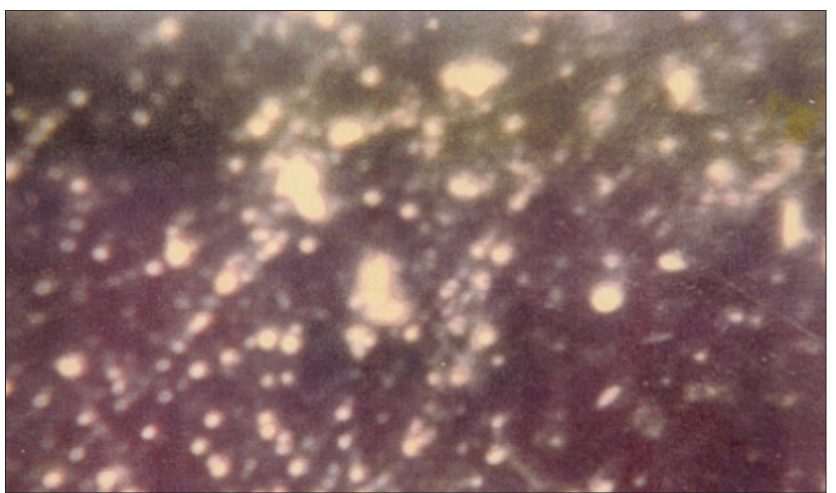

Figure - VII

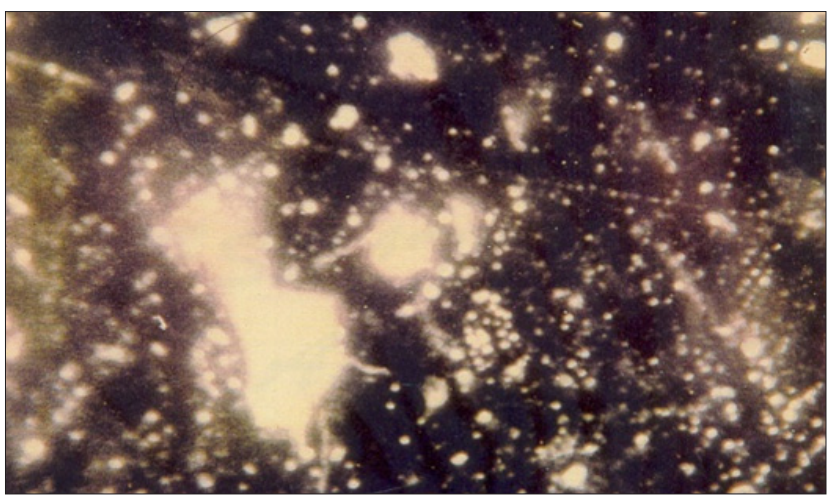

Figure - VIII 
6. Period from the time of initiation of treatment was not more than one year,

7. Teeth were banded or bonded,

8. Individuals who used orthodontic tooth brushes and had no gingival inflammation.

9. To maintain the standardized gingival status for all patients' studies, only those who were tooth brush users free from gingival inflammatory changes were included.

Subjects who had poorly fitting crowns, large carious lesions and unfinished restorations were excluded as these favoured plaque accumulation can introduce bias in the sample.

PROCEDURE : Prior to the commencement of the study, the purpose of the same was explained to each of the subjects and their commitment to adhere to the method was solicited.

At the initial visit a swab of Tincture iodine was applied on the teeth and patient was asked to rinse. The stained plaques were demonstrated to the patient with the aid of a mirror. ${ }^{26}$ the teeth were thoroughly scaled and polished and plaque scores were reduced to zero prior to the commencement of thestudy. The subjects were asked to use a particular tooth brush and a specific brushing technique was taught. Subjects were directed to report every two weeks for collection of plaques samples.

The pooled plaques samples were collected with a sterile curette surface and stored in test tubes containing 1-2 ml of sterile saline solution (Figure I and II). The test tubes werestored in an ice container and studied under dark field microscope within a time frame of one hour. The subjects were given tincture iodine applied with cotton on tooth surface for a minute and were asked to rinseonce with water. The stained plaque (Figure III, IV and V) was recorded using the Bonded Bracket Index and the plaques demonstrated to the patients. Patients were sent back with reinforced tooth brushing instructions. The same patient were recalled again every two weeks for eight weeks and samples collected by the same operator under identical conditions subjected to the same methodology and studied.

\section{ORAL HYGIENE REGIME}

Senolin orthodontic tooth brushes were used for the study. A non-therapeutic tooth paste was recommended and the patients were asked to discontinue any medicated tooth paste, they may have been using at least 15 days prior to the trial.

The bass tooth brushing technique was explained to the subject. ${ }^{27}$ only those who demonstrated proper technique were sel ected. Tooth brushing time was 5 minutes twice daily. The patient was asked to brush at the same time everyday with light pressure and quadrant wise to standardize the procedure.

\section{MICRO SCOPIC EXAMINATION OF PLAQUE}

Dark field or phase contrast microscopy (Figure VI) was used to detect bacterial morphotypes, determine motility and identify spirochetes ${ }^{25,26}$ and to assess the percentage of motile rods / spirochetes in plaque sample (Figure VII and Figure VIII) and were done every two weeks. The Plaque Index was recorded by the same investigator throughout the period of study as described earlier.

QUIGLEY - HEIN INDEX ${ }^{27}$ (used for banded maxillary and mandibular molars):

Was used in the evaluation of the amount of microbial plaque on the whole crown surface and is scored in the following manner.

0: No microbial plaque

1: Spots of microbial plaque at the gingival border.

2: Prominent microbial plaque at the gingival border.

3: Microbial plaque covers a third of the tooth surface near the gingival

4: Two thirds of the tooth surface is covered with microbial plaque. 
5: More than two thirds of the tooth surface is covered with microbial plaque.

Bonded Bracket I ndex was devel oped and used to determine the amount of microbial plaque accumulation on the teeth with the bracket and scored as;

0 - No plaque

1 - Plaque only on the brackets.

2 - Plaque on the bracket and tooth surface but not spreading towards gingival.

3 - Plaque on the bracket and tooth surface spreading to the papilla.

4 - Plaque on the bracket and tooth surface, part of gingival is covered with plaque.

5 - Plaque on the bracket, tooth surface, gingival is totally covered with plaque.

\section{Results:}

Data was analysed using SPSS software. Students paired t-test was employed to test the differences of variables V1 \& V2 at each time points within each study groups. Student's independent t-test was employed to compare the mean values of V1 \& V2 different time points between two independent groups. In the present study $\mathrm{P}<0.05$ was considered as the statistically significant level.

\section{TABLE -I:}

Mean and standard deviation (S.D) for the variables V1\& V2 different time points.

\begin{tabular}{|c|c|c|c|c|c|}
\hline Variable & Time Point & $\begin{array}{c}\text { Group } 1 \\
\text { Mean+S.D } \\
(n=24)\end{array}$ & $\begin{array}{c}\text { Group } 2 \\
\text { Mean+S.D } \\
(n=24)\end{array}$ & $\begin{array}{c}\text { p-Value } \\
\text { (Gp1 vs Gp2) }\end{array}$ & \\
\hline \multirow{4}{*}{$\begin{array}{l}\text { V1 (Plaque } \\
\text { Index) }\end{array}$} & 2 weeks & $1.46 \pm 0.36$ & $1.96 \pm 0.49$ & $\lessdot 0.0001$ & $\mathrm{~S}$ \\
\hline & 4 weeks & $1.60 \pm 0.32$ & $2.11 \pm 0.45$ & $<0.0001$ & $\mathrm{~S}$ \\
\hline & 6 weeks & $1.68 \pm 0.39$ & $2.26 \pm 0.34$ & $<0.0001$ & $\mathrm{~S}$ \\
\hline & 8 weeks & $1.71 \pm 0.37$ & $2.40 \pm 0.48$ & $\Varangle 0.0001$ & $\mathrm{~S}$ \\
\hline \multirow{4}{*}{$\begin{array}{c}\text { V2 (Spirocheates } \\
\text { Count) }\end{array}$} & 2 weeks & $17.92+1.41$ & $30.00 \pm 20.22$ & 0.02 & $\mathrm{~S}$ \\
\hline & 4 weeks & $22.50 \pm 12.25$ & $32.71 \pm 13.27$ & 0.008 & $\mathrm{~S}$ \\
\hline & 6 weeks & $23.96 \pm 16.48$ & $33.75 \pm 15.27$ & 0.038 & $\mathrm{~S}$ \\
\hline & 8 weeks & $18.75 \pm 9.00$ & $34.17 \pm 13.81$ & $<0001$ & $\mathrm{~S}$ \\
\hline
\end{tabular}

* Independent t-test was employed to estimate the p-value.

Table - I gives the mean and standard deviation (S.D) for the variables V1 \& V2 different time points. Also these means were compared between the two groups that are group -1 and group 2 at each time points. The mean values of $\mathrm{V} 1$ at $2^{\text {nd }}, 4^{\text {th }}, 6^{\text {th }}$ and $8^{\text {th }}$ week for group I are $=1.46+0.36,1.60+0.32,1.68+0.39$ and $1.71+$ 0.37 respectively, whereas the same for group II are $=1.96+0.49,2.11+0.45 .2 .26+3.04$ and $2.40+0.48$. All the above values are statistically significant at each time point $(\mathrm{P}<0.0001)$. Thus the group II patients have significantly higher mean values of $\mathrm{V} 1$ at all the time points.

The mean values of V2 at $2^{\text {nd }}, 4^{\text {th }}, 6^{\text {th }}$ and $8^{\text {th }}$ week for group I are $=17.92+11.41,22.50+12.25,23.96+$ 16.48 and $18.75+9.00$ respectively whereas the same for group II are $=30.00+20.22,32.71+13.27,33.75+$ 15.27 and $34.17+13.81$.

All the above mean values are statistically significant at each time point $(P<0.05)$.

Thus the group II patients have significantly higher mean values of $\mathrm{V}_{2}$ at all the time points. 
TABLE -II:

Test of significance for the difference in VI at different time points within each study group.

\begin{tabular}{|c|c|c|c|c|c|c|c|}
\hline Variable & Group & Time Point & $\begin{array}{l}\text { Mean+S.D } \\
\text { Time Point } 1\end{array}$ & $\begin{array}{l}\text { Mean+S.D } \\
\text { Time Point } 2\end{array}$ & $\begin{array}{c}\text { Difference } \\
\text { (II-I) }\end{array}$ & p-value & \\
\hline \multirow[t]{6}{*}{ V1 } & \multirow[t]{6}{*}{ I } & $2 w k$ vs 4 wk & $1.46 \pm 0.36$ & $1.60 \pm 0.32$ & $0.14 \pm 0.34$ & 0.05 & Ns \\
\hline & & $2 w k$ vs 6wk & $1.46 \pm 0.36$ & $1.68 \pm 0.39$ & $0.22 \pm 0.43$ & 0.02 & $\mathrm{~S}$ \\
\hline & & $2 w k$ vs 8wk & $1.46 \pm 0.36$ & $1.71 \pm 0.37$ & $0.25 \pm 0.44$ & 0.01 & $\mathrm{~S}$ \\
\hline & & $4 w k$ vs $6 w k$ & $1.60 \pm 0.32$ & $1.68 \pm 0.39$ & $0.08 \pm 0.23$ & 0.09 & Ns \\
\hline & & $4 w k$ vs $8 w k$ & $1.60 \pm 0.32$ & $1.71 \pm 0.37$ & $0.11 \pm 0.29$ & 0.08 & $\mathrm{~S}$ \\
\hline & & $6 w k$ vs 8wk & $1.68 \pm 0.39$ & $1.71 \pm 0.37$ & $0.03 \pm 0.28$ & 0.62 & Ns \\
\hline \multirow[t]{6}{*}{ V2 } & \multirow[t]{6}{*}{ II } & $2 w k$ vs 4 wk & $1.96 \pm 0.49$ & $2.11 \pm 0.45$ & $0.15 \pm 0.28$ & 0.01 & $\mathrm{~S}$ \\
\hline & & $2 w k$ vs 6wk & $1.96 \pm 0.49$ & $2.26 \pm 0.34$ & $0.31 \pm 0.37$ & $<0.0001$ & $\mathrm{~S}$ \\
\hline & & $2 w k$ vs $8 w k$ & $1.96 \pm 0.49$ & $2.40 \pm 0.48$ & $0.44 \pm 0.37$ & $<0.0001$ & $\mathrm{~S}$ \\
\hline & & $4 w k$ vs $6 w k$ & $2.11 \pm 0.45$ & $2.26 \pm 0.34$ & $0.15 \pm 0.29$ & 0.02 & $\mathrm{~S}$ \\
\hline & & $4 w k$ vs $8 w k$ & $2.11 \pm 0.45$ & $2.40 \pm 0.48$ & $0.29 \pm 0.33$ & $<0.0001$ & $\mathrm{~S}$ \\
\hline & & $6 w k$ vs 8wk & $2.26 \pm 0.34$ & $2.40 \pm 0.48$ & $0.14 \pm 0.41$ & 0.12 & Ns \\
\hline
\end{tabular}

* Paired t-test was employed to estimate the P-value,Ns-N on Significant.

Table II gives the results of test of significance for the difference of $\mathrm{V}_{1}$, at each time points, thin each study group. There is a significant increase in the value of $V_{1}$ at $6^{\text {th }}$ week and $8^{\text {th }}$ week, compared to 2 week $(\mathrm{P}<0.05)$ is group I. None of the other comparisons are statistically significant in group I $(\mathrm{P}>0.05)$.

Similarly, in group II there was a significant $(P \varangle 0.02)$ improvement in $V_{1}$ at all time points except, $6^{\text {th }}$ week vs. $8^{\text {th }}$ week.

\section{Table III :}

Test of significance for the difference of V2 at each time point within each study group.

\begin{tabular}{|c|c|c|c|c|c|c|c|}
\hline Variable & Group & Time Point & $\begin{array}{l}\text { Mean+S.D } \\
\text { Time Point } 1\end{array}$ & $\begin{array}{l}\text { Mean+S.D } \\
\text { Time Point } 2\end{array}$ & $\begin{array}{c}\text { Difference } \\
\text { (II-I) }\end{array}$ & p-value & \\
\hline \multirow[t]{6}{*}{ V1 } & \multirow[t]{6}{*}{1} & $2 w k$ vs 4 wk & $17.92 \pm 11.41$ & $22.5+12.25$ & $4.58 \pm 13.18$ & 0.1 & Ns \\
\hline & & 2wk vs 6wk & $17.92+11.41$ & $23.96 \pm 16.48$ & $6.04 \pm 17.13$ & 0.1 & Ns \\
\hline & & $2 w k$ vs $8 w k$ & $17.92+11.41$ & $18.75 \pm 9$ & $0.83+13.16$ & 0.76 & Ns \\
\hline & & $4 w k$ vs 6wk & $22.50 \pm 12.25$ & $23.96 \pm 16.48$ & $1.46+13.15$ & 0.59 & Ns \\
\hline & & $4 w k$ vs $8 w k$ & $22.50 \pm 12.25$ & $18.75 \pm 9$ & $3.75 \pm 10.56$ & 0.1 & Ns \\
\hline & & $6 w k$ vs 8wk & $23.9 \pm 16.48$ & $18.75 \pm 9$ & $5.21 \pm 13.63$ & 0.07 & Ns \\
\hline \multirow[t]{6}{*}{ V2 } & \multirow[t]{6}{*}{ II } & $2 w k$ vs 4 wk & 30. \pm 20.22 & $32.71 \pm 13.27$ & $2.71+19.62$ & 0.51 & Ns \\
\hline & & $2 w k$ vs 6wk & 30. \pm 20.22 & $13.75 \pm 15.27$ & $3.75 \pm 23.37$ & 0.44 & Ns \\
\hline & & $2 w k$ vs $8 w k$ & 30. \pm 20.22 & $34.17 \pm 13.81$ & $4.17+19.32$ & 0.3 & Ns \\
\hline & & $4 w k$ vs $6 w k$ & $32.71 \pm 13.27$ & $33.75 \pm 15.27$ & $1.04+17.69$ & 0.78 & Ns \\
\hline & & $4 w k$ vs $8 w k$ & $32.71 \pm 13.27$ & $34.17 \pm 13.81$ & $1.46 \pm 16.25$ & 0.66 & Ns \\
\hline & & $6 w k$ vs 8wk & $33.75 \pm 15.27$ & $34.17 \pm 13.81$ & $.42+16.81$ & 0.9 & Ns \\
\hline
\end{tabular}

* Paired t-test was employed to estimate the P-value.

Table III gives the results of test of significance for the difference of V2 at each time point, within each study group. 
None of the differences are statistically significant $(P>0.05)$ for both group I \& II .

Thus we can conclude that there is a significant difference between group I and II for variables V $1 \&$ V2 at each time point. Also the group II patients are showing significant increase in plaque index value at each point. Hence $\mathrm{V} 1$ is a better index, which is less in group I patients.

\section{Discussion:}

Orthodontic treatment is to a great extent dependent on the biological response of the periodontal tissues. ${ }^{28}$ An important factor which contributes to periodontal disease is plaque formation.

Plaque is a dynamic entity being constantly removed by brushing and it builds up in areas of stagnation. Dental plaque consists of gram +ve cocci like St.sangius, St. Mutans, Gram -ve cocci like Neisseria, Gram +ve rods like Actinomyces I sraeli, Corynebacterium, Gram -ve rods like Bacteroid Melanogenicus, Bacteroid Intermedius, Spirochetes like Treponema Microdentium, Treponema Ovale.29

The commonly used fixed orthodontic appliances are Begg's \& Straight wire. The Begg's bracket occupies less area on the tooth surface, and round wires are used in this technique. Thetooth movement involved is tipping.

The straight wire appliances bracket configuration and slot size are larger. Round and rectangular wires are fixed to the brackets with modules and these areas could cause increased plaque accumulation. Bodily tooth movement is achieved with this technique ${ }^{26}$.

Evaluation of quality of plaque in patient undergoing treatment with straight wire appliances and Begg's appliances has not been reported. The sample in this study consisted of selected patients from the Department of Orthodontics, Saveetha Dental College \& Hospitals. The results can thus be interpreted only for the subjects included and not the general population and only right handed individuals were selected for this study. ${ }^{30}$

Subjects were instructed on the bass technique and horizontal motion was used for remove the food debris and plaque from surface of bands and brackets. $^{31}$ This method has proved to be effective for subjects with a healthy oral cavity and is appropriate for subjects with gingivitis, since it removed plaque from vulnerable gingival areas.

Oral prophylaxis was carried out during the period of treatment to bring down the gingival index score to near zero at the start of the experimental period. ${ }^{26} \mathrm{~A}$ non-therapeutic tooth paste was used during this period to avoid any possible effect of active ingredients of the dentifrice on the plaque formation or gingivitis. The brushing duration was recommended for 5-8 minutes, since each area require 4 strokes. ${ }^{32}$

All 46 subjects weresubjected to oral prophylaxis to bring the plaque score to zero before the start of the experiment and were done to standardise the base line data. All selected subjects were plaque formers.

The subjects were asked to report every 2 weeks to identify the microbial shift in plaque sample.

The organisms usually found were mature, smooth surface dental plaque between $7^{\text {th }}$ and $14^{\text {th }}$ day, are spirochetes. ${ }^{33}$ The plaque samples were collected in $2 \mathrm{ml}$ of saline containing test tubes and were kept in ice containers to bring down the oral temperatures as at higher temperatures, the motility of spirochetes is lost.

In dentistry, it is used to identify bacterial plaque deposits for instruction evaluation and research. RAYBIN (1943) defined as "A solution which when applied to teeth makes visible by staining, roughness and foreign matter on the teeth".

A variety of disclosing agents have been used by clinicians and researchers, like mercurochrome preparations, Bismarck brown (Easlicks disclosing solution), Merbromin, Erythrosine, Fast green, Flourescin, Two-tone, Basic fuschin and Iodine solutions. ${ }^{34}$

I odine solution $(21 \mathrm{ml}$ of tincture I odine of 15 $\mathrm{ml}$ of water) is formally the most classic disclosing solution, is widely used and very effective, but has a drawback, that its flavour is unpleasant.

The disclosing solution was applied on the labial and lingual surfaces of the teeth and the plaque was scored with help of QUIGLY \& HEINS index. ${ }^{27}$

Other indices are Green \& Vermillon, Loe \& Sillness ${ }^{35}$. These are restricted to study tooth surfaces but not indicated when banded or bonded teeth are concerned. 
Dark field microscope studies have been widely used to successfully differentiate population with and without active periodontal destruction and assess the results and monitor therapy. All these are based on the assessment of the percentage of spirochetes, motile bacteria. Healthy patient sites manifest a flora, predominantly gram +ve cocci form with scanty motile forms and spirochetes. ${ }^{36}$

The dark field microscope has the distinct advantage, that a reflected light is used (as against transmitted light in an ordinary microscope) in a dark field to improve the contrast. The contrast gives an increased resolution so that the slender organisms such as spirochetes, their motility and morphology can be seen under dark field microscope.

These techniques have demonstrated that the number and proportion of bacteria morphotypes varied in periodontal health when compared with diseased sites. ${ }^{37}$

Hence studying the bacterial morphotypes, the periodontal condition can be assessed. This is made use of, in this particular study to compare the periodontal condition, during 2 different orthodontic techniques.

\section{Summary and Conclusion:}

The configuration of the straight wire brackets is greatly responsible for increase in plaque accumulation in straight wire appliance when compared with Begg's appliance.

It is possible that increase in size of the bracket encroaches upon the tooth and gingival causing inflammation resulting in gingivitis and increase in the spirochetes also.

While studying the different (techniques) groups, increased plaqueaccumulation in both Begg's and Straight wire appliance has been noticed. The patients take at least a period of six weeks to get used to the Bass technique and practice it regularly to maintain a stable oral hygiene status.

While studying, the increase in the plaque proportion of spirochetes, there is significant difference between the groups. The subjects in group II showing greater increase in the proportion of spirochetes than group I suggest that in subjects with straight wire appliance there is a greater shift towards pathogenic flora than the Begg's appliance.
After six weeks, due to constant and periodical oral hygiene procedures the ability to maintain oral hygiene improves and reduces the plaque accumulation. However, over the eight weeks period plaque accumulation was more in straight wire appliance than Begg's .This shows that Inspite of maintaining same environment the plaque accumulation and spirochetes are more in straight wire appliance than Begg's and the flora is shifting to more pathogenic form.

This point to the need that those having straight wire appliance, the oral hygiene instructions should be more strictly enforced and periodic oral prophylaxis must beresorted to prevent theinitiation of periodontal disease.

It has now been convincingly demonstrated that, even on a short-term basis (1 to 3 years), persons who receive frequent prophylaxis and personal oral hygiene instruction have cleaner teeth, less carious involvement, less gingival inflammation, a slower rate of apical migration of the epithelial attachment, and less bone loss radiographically than persons not receiving Such attention. ${ }^{38}$

\section{References:}

1. Feliu J L. Long-term benefits of orthodontic treatment on oral hygiene. Am J Orthod 1982; 82:473-477

2. Poison AM, Subtelny J D, Meitner SW, Sonmrers EW, Iker $\mathrm{HP}$, Reed BE. Long-term periodontal status after orthodontic treatment. Am J Orthod Dentofac Orthop 1988; 93:51-58.

3. Boyd RL, Murray, P, Robertson PB. Effect of rotary electric toothbrush versus manual tooth brush on periodontal status during orthodontic treatment. Am J Orthod Dentofac Orthop 1989; 96:342-347.

4. Hannah J J, J ohnson J D, Kuftinec MM. Long-term clinical evaluation of toothpaste And oral rinse containing sanguinaria extract in controlling plaque, gingival inflammation, and sulcular bleeding during orthodontic treatment. Am J Orthod Dentofac Orthop 1989; 96:199-207.

5. Huber S J , Vernino AR, Nanda RS. Professional prophylaxis and its effect on the Periodontium of full-banded orthodontic patients. Am J Orthod Dentofac Orthop 1987; 91:321-327.

6. J ackson CL. Comparison between el ectric tooth brushing and manual tooth brushing, With and without oral irrigation, for oral hygiene of orthodontic patients. Am J Orthod Dentofac Orthop 1991; 99:15-20.

7. Tunali B. Periodontoloji ve Oral implantoloji'de Klinik Parametre ve indeksler. Istanbul: As Matbaa ve Tic. A. ., 1994:19. 
8. Wilcoxon DB, Ackerman RJ, Killoy WJ, Love J W, Saknmura J S, Tira D. The Effectiveness of a counter rotational-action power toothbrush on plaque control in orthodontic patients. Am J Orthod Dentofac Orthop 1991; 99:7-14.

9. Yeung, S. C., Howell, S. and Fahey, P. (1989) Oral hygiene program for orthodontic patients, American J ournal of Orthodontics, 93, 208-213.

10. Lundstrom, F. (1985) Promoting Dental Health in Orthodontic Patients, Trych-center AB, Linkoping.

11. Denes, J . and Gabris, K. (1991) Results of a 3-year oral hygiene programme, including amine fluoride products, in patients treated with fixed orthodontic

12. Wilcoxon, D. B., Ackerman, R. J ., Killoy, W. J ., Love, J . W., Sakumura, J . S. and Tira, D. E. (1991) The effectiveness of a counter-rotational-action power toothbrush on plaque control in orthodontic patients, American J ournal of Orthodontics, 99:7-14.

13. J ackson, C. L. (1991) Comparison between electric toothbrushing and manual tooth brushing, with and without oral irrigation, for oral hygiene of orthodontic patients, American J ournal of Orthodontics, 99: 15-20.

14. Brightman, L. J ., Terezhalmy, G. T., Greenwell, H., J acobs, M. And Endlow, D. H. (1991) The effects of a 0.12 per cent Chlorhexidine gluconate mouth rinse on orthodontic patients aged 11 through 17 with established gingivitis, American J ournal of Orthodontics, 100: 324-329

15. Pontier, J . P., Pine, C., J ackson, D. L., DiDonato, A. K., Close, $J$.and Moore, P. A. (1990) Efficacy of a pre-brushing rinse for orthodontic patients, Clinical Preventive Dentistry, 12: 1217.

16. Boyd, R. L. (1992) Two-year longitudinal study of a peroxide fluoride rinse on decalcification in adolescent orthodontic patients, J ournal of Clinical Dentistry, 3: 83-87.

17. Boyd, R. L. (1993) Comparison of three self-applied topical fluoride preparations for control of decalcification, Angle Orthodontist, 63: 25-30.

18. Boyd, R. L. and Chun, Y. S. (1994) Eighteen-month evaluation of the effects of a 0.4 per cent stannous fluoride gel on gingivitis in orthodontic patients American J ournal of Orthodontics, 105: 35-41.

19. Boyd, R. L., Murray, P. and Robertson, P. B. (1989) Effect of rotary electric toothbrush versus manual toothbrush on periodontal status during orthodontic treatment, American J ournal of Orthodontics, 96: 342-347.

20. Zachrisson, B. U., and Zachrisson, S. Caries incidence and oral hygiene during orthodontic treatment, Stand. J . Dent. Res. 1971; 79: 394-401.

21. Lindhcs,I., and Axelsson, I'. The effect of controlled oral hygiene and topical fluoride application on wires and gingivitis in Swedish schoolchildren, Community Dent. Oral Epidemiology. 1: 9-16, 1973

22. Suomi, J . D., Greene, J . C., Vermillion, J . R., Doyle, J ., Chang, J . J ., and Leatherwood, E. C.: The effect of controlled oral hygiene procedures on the progression of periodontal disease in adults: Results after third and final year, J . Periodontol. 1971; 42: 152-160.

23. Zachrisson S, Zachrisson BU. Gingival condition associated with orthodontic treatment. Angle Orthod 1972; 42:26-34.

24. Schwaninger B, Vichers-Schwaninger N. Developing an effective oral hygiene program for the orthodontic patients: review, rationale, and recommendations. Am j orthod 1979;75:447-52

25. Bobby L. Butler, Oscar Morejon, Samuel B. Low. Assessment of plaque accumulation J .A.D.A 1996; 127(2), 1763 -1766

26. Clark J.R. Oral hygiene in the orthodontic practice, motivation, responsibility and concepts. Am.J .of Orthod 1976; 69: 72 - 82.

27. Davies, T.M, Shaw, W.G, Worthington, H. V. Effect of orthodontic treatment on Plaque and gingivitis. Am.J .of Orthod, 1991;99:155-160

28. Dikeman T.L: Study of Acidogenie and Aciduric micro organisms in orthodontic and non-orthodontic patients. Am. J. Orthod, 1962; 48: 627 - 662

29. Donald.B. Willcoxon, William J .Killody, Daniel. E. Tira. The effectiveness of counter rotational action power tooth brush on plaque control in orthodontic patients. Am.J .of Orthod 1991; 99: 7- 14

30. Fredrik Lundstrom, BoKrsse. St.cocci mutans and lactobacilli frequency in orthodontic patients. Eu. J .Orthod 1987; 9: 109116.

31. Gwinett. A.J ., Ceen. R.F. SEM study - plaque distribution on orthodontic brackets. Am.J .of Orthod 1979; 75: 667-677

32. Hamp .S.E, Lundstrom .F, Nymann .S. Periodontal conditions in adolescents subjected to multiband Orthodontic treatment with controlled oral hygiene. Euro. J . of Orthod: 4: 77 - 86, 1982.

33. Huber S.J , Vemino A.R, Nanda R.S. Professional prophylaxis and its effect on the periodontium of full banded orthodontic patients. Am J of Orthod, 1987; 91:321-326.

34. Hulya Kilocoglu, Melek Yildir. Comparison of the effectiveness of twotypes of tooth brushes on the oral hygiene of patients undergoing orthodontic treatment with fixed appliance. Am J of Orthod 1997; Vol 111: 591-594.

35. Iyer V.S. Reaction of the gingival to orthodontic force. A critical study. J ournal of periodont 1962; 33:26-29.

36. J ackson CL. Comparison between el ectric tooth brushing and manual tooth brushing with and without oral irrigation for oral hygiene of Orthodontic patients. Am J of Orthod 1991; 99:15-20.

37. Listgarten M.A. : Structure of microbial flora associated with periodontal health and disease in man. A light and electron microscopic study. J . of periodont 1976; 47: 1.

38. Zachrisson, B. U., and Alnms, L.: Periodontal condition in orthodontically treated and untreated individuals. I. Loss of attachment, gingival pocket depth and clinical crown height, Angle Orthod. 1973; 43: 402-412. 